\title{
Análise físico-química e microbiológica do leite cru comercializado
} em Roraima

\author{
Riane Castro de Moura ${ }^{1}$, Juciel Silva Sousa ${ }^{1}$, Rita de Cássia Ferreira ${ }^{2}$, Ivanise Maria \\ Rizzatti $^{1}$
}

1. Universidade Estadual de Roraima. (UERR). Campus Boa Vista, Curso de Licenciatura em Química, Rua Sete de Setembro 231, Canarinho CEP 69306-530C, Boa Vista, RR, Brasil.

2. Universidade Estadual de Roraima. (UERR). Campus Boa Vista, Curso de Bacharelado em Enfermagem, Rua Sete de Setembro 231, Canarinho CEP 69306-530C, Boa Vista, RR, Brasil.

*E-mail para correspondência: niserizzatti@gmail.com

Recebido em: 05 de abril de 2017. Aceito em: 24 de junho de 2017. Publicado PDF em: 03 de julho de 2017

\section{RESUMO}

Análise físico-química e microbiológica do leite cru comercializado em Roraima. O presente trabalho analisou os parâmetros físicos, químicos e microbiológicos de 13 amostras de leite in natura ou cru fluido comercializadas em Roraima, nos municípios de Cantá, Alto Alegre e Boa Vista, com o intuito de verificar sua adequação às legislações brasileiras em vigor. Os parâmetros analisados foram temperatura, $\mathrm{pH}$, prova Dornic, acidez em ácido láctico, estabilidade ao etanol, prova de amido, água oxigenada, extrato seco total, cloro e hipocloritos, sacarose, determinação de cálcio, leite colostral, coliformes totais e fecais, e salmonela. O resultado das análises mostrou que $100 \%$ das amostras de leite in natura avaliadas estavam dentro dos padrões regulamentados para substâncias fraudulentas. Entretanto, os parâmetros que se apresentaram em desacordo foram temperatura (100\%), teor de cálcio $(100 \%)$, acidez em graus Dornic (62\%), estabilidade ao etanol (31\%), extrato seco total (15\%), colostro (8\%), $100 \%$ das amostras apresentaram presença de coliformes totais, $85 \%$ coliformes fecais e $77 \%$ das amostras indicaram a presença de salmonela.

PALAVRAS CHAVE: Leite bovino; Condições higiênico-sanitárias; Qualidade do leite .

\begin{abstract}
Physical-chemical and microbiological evaluation of raw milk commercialized in Roraima. This study examined the physicalchemical and microbiological samples of 13 raw milk or raw fluid in Roraima state in the municipalities of Cantá, Alto Alegre and Boa Vista, in order to verify its suitability to the Brazilian legislation. The physical-chemical properties were analyzed: temperature, $\mathrm{pH}$, proof Dornic, acidity lactic acid, ethanol stability, proof of starch, hydrogen peroxide, total solids, chlorine and hypochlorite, sucrose, calcium determination, colostrum milk and analyzes microbiological fecal coliforms, total coliforms and salmonella. All important for the identification of a milk quality. The result of the analysis showed that $100 \%$ of the raw milk samples were evaluated within the standards for regulated substances fraudulent. However, the parameters that were presented at odds temperature (100\%), calcium content (100\%), acidity degrees Dornic (62\%), stability to ethanol (31\%), total solids (15\%), colostrum (8\%) and microbiological showed that for all samples the presence of total coliforms, fecal coliforms $85 \%$ and $77 \%$ of the samples indicated the presence of salmonella.
\end{abstract}

KEY WORDS: Bovine milk; Hygienic-sanitary conditions; Milk quality.

\section{INTRODUÇÃO}

Desde os primórdios da civilização, o leite tem sido utilizado na alimentação humana como fonte de proteína, gordura, energia e outros constituintes essenciais. Sendo considerada a primeira fonte de nutrientes para os mamíferos e a maior fonte de cálcio absorvível à disposição do homem (Trevisan 2008).

$\mathrm{O}$ leite e seus derivados estão entre os alimentos mais consumidos no mundo, por ser um alimento altamente nutritivo e essencial na alimentação humana, estando sujeito a fraudes e a transmissões de doenças caso não tenha um eficiente controle de qualidade.

A qualidade do leite in natura é influenciada por muitas variáveis, entre as quais se destacam os fatores zootécnicos associados ao manejo, alimentação, potencial genético dos rebanhos e fatores relacionados à obtenção e armazenagem 
do leite. Dentre os fatores que exercem influência extremamente prejudicial sobre a composição e as características físico-químicas do leite, destaca-se a mastite, que se caracteriza por uma inflamação das glândulas mamárias, acompanhada por um aumento na contagem de células somáticas (CCS) (Müller 2002).

Portanto, o controle desse alimento deve ser realizado com rigor, para que não ocorram mais casos como o veiculado na mídia recentemente, no qual centenas de litros de leites foram adulteradas no Rio Grande do Sul, com adição de uréia e água, colocando em risco a saúde dos consumidores.

De acordo com o Instituto Brasileiro de Geografia e Estatística (IBGE 2012), a cada dez litros de leite produzido em todo país, três não passam por nenhum tipo de fiscalização (Fiuza 2013). Atualmente, o Brasil vem se destacando entre os principais produtores de leite do mundo, mas carrega dois problemas difíceis de serem resolvidos, a má qualidade do leite e a condição sanitária dos estabelecimentos. Essa situação se deve a existência de um grande número de estabelecimentos que desenvolvem a atividade leiteira, mas em condições ainda precárias (Zoccal et al. 2011).

O comércio informal de leite é uma grande ameaça à saúde pública visto que, segundo a Organização Mundial de Saúde (OMS), dezesseis doenças bacterianas e sete viróticas são veiculadas pelo produto, dentre elas, a tuberculose, brucelose e gastroenterites, sendo esta uma grave consequência da baixa qualidade do leite proveniente do mercado informal (Mendes et al. 2006).

Em Roraima, a prática da produção leiteira é desenvolvida, principalmente, por agricultores familiares (IBGE 2012), sem os cuidados mínimos com relação às condições higiênicosanitárias. De acordo com SEBRAE/RR (2010), os mercados consumidores de leite e derivados no estado ficam concentrados em Boa Vista, correspondendo a $49,10 \%$ do total que é produzido, e o restante é vendido nas vizinhanças das fazendas ou nas cidades do interior. A pesquisa também apontou que $62,6 \%$ dos produtores de leite não produzem nenhum subproduto, enquanto que os demais produzem queijo coalho, manteiga, doce de leite e iogurte.

O leite produzido nessas unidades rurais, geralmente não passa por nenhuma análise de controle de qualidade e são comercializados in natura em pontos de venda diversificados em todo o estado (SEBRAE 2010).

Nesse contexto, este trabalho visa avaliar os parâmetros físicos, químicos e microbiológicos de amostras de leite in natura ou cru fluido comercializadas nos municípios de Alto Alegre, Cantá e Boa Vista, e comparar os resultados com a legislação nacional vigente.

\section{MATERIAL E MÉTODOS}

\section{Material}

Inicialmente, realizou-se a identificação de alguns produtores de leite que comercializam o produto e pontos de vendas nos municípios de Cantá, Boa Vista e Alto Alegre, para identificar os pontos de coleta das amostras, uma vez que esses municípios são os responsáveis por quase toda a produção de leite em Roraima. . Além disso, foi elaborado um questionário para ser aplicado aos produtores e/ou vendedores de leite, com intuito de obter informações higiênico-sanitárias durante o processo de ordenha e comercialização deste alimento.

A pesquisa foi realizada no leite in natura ou cru fluido nos municípios de Cantá, Boa Vista e Alto Alegre (Figura 1), no ano de 2013. E os pontos de coleta (Tabela 1) foram georreferenciados através do Global Positioning System (GPS), utilizando o equipamento GARMIN etrex ${ }^{\circledR}$ - vista HCX.

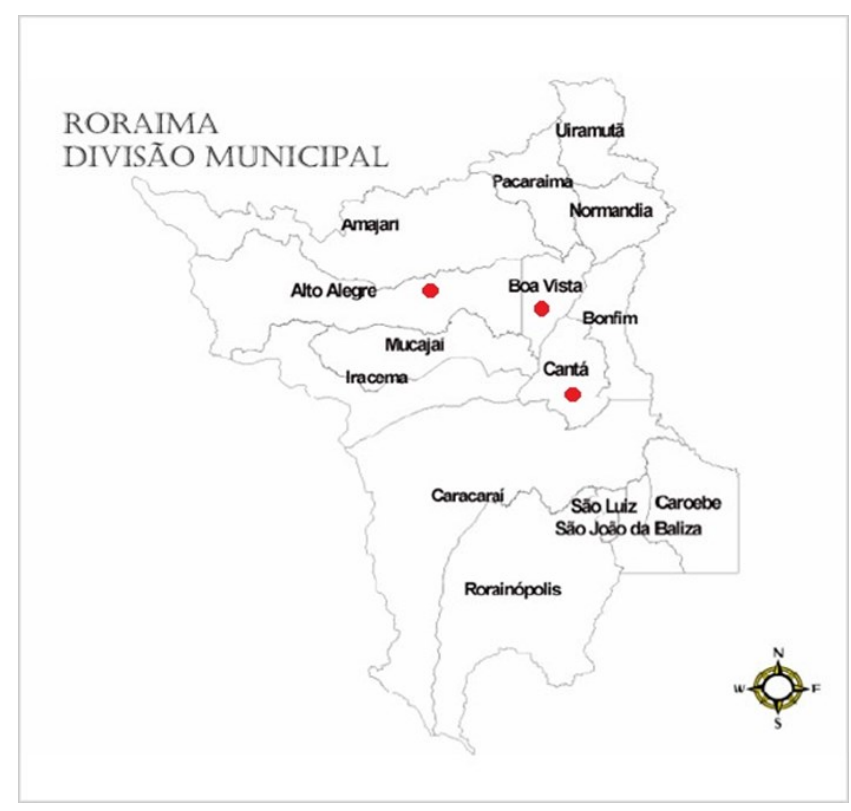

Figura 1. Mapa geopolítico de Roraima identificando os municípios nos quais foram realizadas as coletas das amostras de leite in natura. Fonte: http:// www.trilhasdeconhecimentos.etc.br/roraima/ divisao_municipal.htm 
Tabela 1. Local dos pontos de coleta das amostras de leite in natura nos municípios de Cantá (CT), Boa Vista (BV) e Alto Alegre (AL), Roraima.

\begin{tabular}{|c|c|c|}
\hline Amostra & Localização Geográfica & Local de Coleta \\
\hline CT1 & 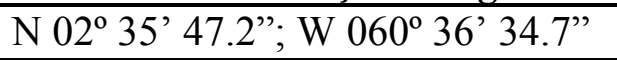 & Propriedade rural \\
\hline $\mathrm{CT} 2$ & $\mathrm{~N} 02^{\circ} 36^{\prime} 36.5^{\prime \prime} ; \mathrm{W} 060^{\circ} 35^{\prime} 58.2^{\prime \prime}$ & Ponto comercial \\
\hline CT3 & N 02 36' 41.5”; W 060'36' 15.2” & Ponto comercial \\
\hline CT4 & N 02³6'33.7”; W $060^{\circ} 35^{\prime}$ 57.2” & Ponto comercial \\
\hline BV1 & N 0249' 95.7”; W $060^{\circ} 39^{\prime} 55.9^{\prime \prime}$ & Ponto comercial \\
\hline BV2 & 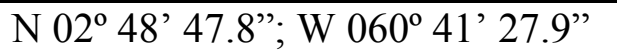 & Ponto comercial \\
\hline BV3 & N 02 48' 05.9”; W 060 40' 50.7" & Ponto comercial \\
\hline AL1 & N 02 59’ 06.7”; W 061²0’ 08.5” & Propriedade rural \\
\hline AL2 & $\mathrm{N} 02^{\circ} 57^{\prime} 16.1^{\prime \prime} ; \mathrm{W} 061^{\circ} 19^{\prime} 37.3^{\prime \prime}$ & Propriedade rural \\
\hline AL3 & $\mathrm{N} 02^{\circ} 59^{\prime} 34.8^{\prime \prime} ; \mathrm{W} 061^{\circ} 18^{\prime} 41.1^{\prime \prime}$ & Ponto comercial \\
\hline AL4 & 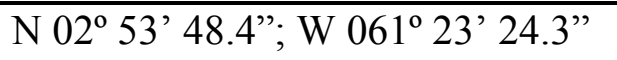 & Propriedade rural \\
\hline AL5 & $\mathrm{N} 02^{\circ}$ 53'33.3”; W 061 23'06.6" & Propriedade rural \\
\hline AL6 & 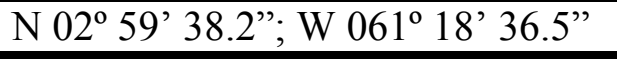 & Ponto comercial \\
\hline
\end{tabular}

\section{Métodos}

Foram coletadas 13 amostras de leite in natura em garrafas plásticas tipo PET's (previamente limpas e higienizadas), e em saquinhos plásticos (amostras vendidas em alguns estabelecimentos comerciais).

Para as análises físico-químicas e microbiológicas foram coletadas amostras acondicionadas em uma caixa térmica, e transportadas imediatamente para o Laboratório de Química da Universidade Estadual de Roraima (UERR). Todas as soluções foram preparadas em água destilada, e as soluções dos titulantes devidamente padronizadas. Todos os reagentes utilizados eram de grau P.A. A determinação da acidez em ácido láctico, acidez em graus Dornic, estabilidade ao etanol, extrato seco total, identificação de amido, prova de sacarose, cloro e hipocloritos, foram realizadas conforme estabelecido pelo Instituto Adolfo Lutz (2005). As determinações de água oxigenada e de leite colostral foram realizadas conforme recomendado pelo Manual de Inspeção da Qualidade do Leite (Tronco 2010) e a determinação de cálcio conforme sugerido por Vogel (2002).

Os resultados obtidos foram comparados com os estabelecidos pela Instrução Normativa 062/11(BRASIL 2011) e 068/06 (BRASIL 2006) e RIISPOA (BRASIL 1980). Para a determinação dos parâmetros físico-químicos do leite, as amostras foram homogeneizadas e, em seguida, retiradas alíquotas para determinação, em triplicata.

\section{Análises físico-químicas}

Os parâmetros de $\mathrm{pH}$ e a temperatura foram determinados utilizando um pHmetro portátil da marca HANNA, modelo 424. Para a leitura, as amostras foram previamente homogeneizadas, e após, imergiu-se o eletrodo de vidro e a sonda de temperatura nas amostras, aguardou-se o período de estabilização e em seguida, realizou-se a leitura de cada amostra.

Para a determinação da acidez em ácido láctico transferiu-se $10 \mathrm{~mL}$ da amostra para um erlenmeyer de $100 \mathrm{~mL}$, adicionou-se 5 gotas de fenolftaleína e, em seguida, titulou-se com solução de hidróxido de sódio $0,1 \mathrm{M}$ previamente padronizada, até o aparecimento da coloração rósea (Instituto Adolfo Lutz 2005).

Para o cálculo de ácido láctico, utilizou-se a equação 1:

Ácido láctico por cento $\mathrm{m} / \mathrm{v}=\frac{\mathrm{Vx} \mathrm{f \times 0,9}}{\mathrm{A}}$

Onde:

$\mathrm{V}=\mathrm{n}^{\mathrm{o}}$. de $\mathrm{mL}$ da solução de hidróxido de sódio $0,1 \mathrm{M}$ gasto na titulação;

$\mathrm{f}=$ fator de correção da solução de hidróxido de sódio $0,1 \mathrm{M}$;

$\mathrm{A}=\mathrm{n}^{\mathrm{o}}$ de $\mathrm{mL}$ da amostra;

$0,9=$ fator de conversão para ácido láctico

Para a estabilidade ao etanol a $68 \%$ (teste do 
Para a estabilidade ao etanol a $68 \%$ (teste do álcool), adicionou-se, em um tubo de ensaio, 2 $\mathrm{mL}$ de leite e $2 \mathrm{~mL}$ de álcool a $68 \%$, misturouse cuidadosamente e observou-se o resultado foi positivo ou negativo para o teste do álcool (Instituto Adolfo Lutz 2005).

A determinação do extrato seco total (resíduo seco a $105^{\circ} \mathrm{C}$ ), inicialmente, pesou-se em uma cápsula de porcelana $10 \mathrm{~g}$ de areia purificada. Secou-se em estufa Equilam Aiset ${ }^{\circledR}$ Digital modelo YLD-200 a $103 \pm 2{ }^{\circ} \mathrm{C}$ por 2 horas, em seguida, resfriadas em dessecador, e após, pesadas. Transferiu-se $5 \mathrm{~mL}$ da amostra para a cápsula anterior e, misturou-se o leite e a areia. Em seguida, as cápsulas com as amostras foram levadas para secagem em um banhomaria marca SOLAB modelo SL-150/10, após foram levadas para estufa a $103 \pm 2{ }^{\circ} \mathrm{C}$ por 1 hora, resfriadas novamente em dessecador e após, pesadas. Retornou-se à estufa por mais 30 minutos, resfriou-se em dessecador e, pesou-se novamente para obter peso constante.

Para o cálculo, utilizou-se a equação 2 :

Resíduo seco por cento $\mathrm{m} / \mathrm{v}=\frac{100 \times \mathrm{P}}{\mathrm{A}}$

Onde:

$\mathrm{P}=\mathrm{n}^{\circ}$ de $\mathrm{g}$ de resíduo seco

$\mathrm{A}=\mathrm{n}^{\circ}$ de $\mathrm{mL}$ da amostra

Na identificação de amido, mediu-se $10 \mathrm{~mL}$ da amostra em uma proveta e transferiu-se para um béquer, que foi aquecida até ebulição em chapa aquecedora. Resfriou-se e adicionou-se 2 gotas de solução de Lugol, aguardando se a reação foi positiva ou negativa para a presença de amido (Instituto Adolfo Lutz 2005).

Para a determinação de cloro e hipocloritos, em tubo de ensaio, transferiu-se $5 \mathrm{~mL}$ da amostra, adicionou-se $0,5 \mathrm{~mL}$ de solução de iodeto de potássio sob agitação e observou-se o resultado. $\mathrm{O}$ aparecimento da coloração amarela indica a presença de cloro livre. Nas amostras não foi necessário o procedimento a seguir, pois não ocorreu a reação, ou seja, não desenvolveu a cor amarela (Instituto Adolfo Lutz 2005).

$\mathrm{Na}$ determinação de cálcio, $10 \mathrm{~mL}$ de amostra, adicionou-se $30 \mathrm{~mL}$ de água destilada, $2 \mathrm{~mL}$ de solução tampão de cloreto de amônio saturado e 2 gotas de solução de Negro Eriocromo T, titulou-se com solução de EDTA $0,01 \mathrm{M}$, previamente padronizada até a mudança da coloração violeta para azul. Anotou-se o volume gasto e calculou-se o teor de cálcio nas amostras considerando que para cada $1 \mathrm{~mL}$ de EDTA corresponde a 0,4008 mg de Cálcio (Vogel 2002).

Para a determinação de água oxigenada, em um tubo de ensaio, colocou-se $5 \mathrm{~mL}$ de leite e, em seguida, adicionou-se 3 gotas de Lugol e observou-se o resultado. A reação é indicada pela coloração amarela.

$\mathrm{Na}$ determinação da sacarose, transferiu-se 2 $\mathrm{mL}$ de leite e $0,5 \mathrm{~mL}$ de ácido clorídrico P.A., incubou-se em banho-maria por 1 minuto e observou o resultado.

\section{Análises microbiológicas - Análise de coliformes fecais, totais e salmonela}

Para a análise de salmonela, coliformes fecais e totais, utilizou-se o método Colipaper $\circledR$, que consiste em uma cartela com meio de cultura em forma de gel desidratado usado para análise microbiológica. A presença de coliformes fecais é confirmada pela contagem de pontos azuis, a de coliformes totais, pontos azuis e pontos vermelhos e para salmonela, a contagem de pontos verdes que desenvolvem na cartela após o período de incubação, todos multiplicados por 100 para obtenção das Unidades Formadoras de Colônias, UFC/100 $\mathrm{mL}$.

Para tanto, transferiu-se $80 \mathrm{~mL}$ da amostra para imersão da cartela microbiológica, retirouse o excesso de leite, e em seguida, a cartela foi recolada na embalagem plástica, levou-se à estufa digital microprocessada para cultura bacteriológica marca Sterilifer Modelo SX 1,2 DTMC por 24 horas a temperatura de $36-$ $37^{\circ} \mathrm{C}$. Após 24 horas de incubação, procederam-se à contagem das colônias, considerando os dois lados da cartela.

Verificou-se a necessidade de analisar a eficácia da fervura do leite in natura. Para isto, transferiu-se $80 \mathrm{~mL}$ da amostra para aquecimento até atingirem a fervura a aproximadamente $100{ }^{\circ} \mathrm{C}$. Deixou-se resfriar a amostra e procedeu-se conforme metodologia descrita acima para determinação de coliformes totais, fecais e salmonella, contudo agora empregando a amostra fervida.

\section{Análise estatística}

Os resultados das contagens de microrganismos e das determinações de $\mathrm{pH}$ e 
acidez foram submetidos aos cálculos de média e desvio padrão (Vogel 2002).

\section{RESULTADOS E DISCUSSÃO}

\section{Análises físico-químicas}

A análise das 13 amostras de leite in natura ou cru fluido coletadas nos municípios de Alto Alegre, Cantá e Boa Vista, Roraima, a média e o desvio padrão dos resultados das análises físico-químicas de $\mathrm{pH}$, temperatura, acidez em termos de ácido láctico (A.L.) e graus Dornic $\left({ }^{\circ} \mathrm{D}\right)$, estabilidade e cálcio são apresentados na Tabela 2, e para etanol, amido, cloro, água oxigenada, colostro e sacarose na Tabela 3.

Observando-se os valores obtidos para $\mathrm{pH}$, apresentados na Tabela 3, verificou-se que apenas uma amostra (BV3) apresenta $\mathrm{pH}$ igual a 6,30, o leite recém-ordenhado deve apresentar $\mathrm{pH}$ ligeiramente ácido entre 6,6 e 6,8. Assim, $92 \%$ das amostras, em relação à acidez atual ou aparente $(\mathrm{pH})$, encontram-se dentro dos padrões estabelecidos.

Em relação a temperatura, $100 \%$ das amostras apresentaram valores acima do permitido após a ordenha, com temperaturas variando entre 18,20 e $29,20{ }^{\circ} \mathrm{C}$. Segundo Santos (2010), a temperatura máxima de conservação do leite na propriedade rural é de $7^{\circ} \mathrm{C}$, devendo ser mantido refrigerado até seu transporte para a indústria, sendo que a refrigeração deve ocorrer no tempo máximo de três horas após o término da ordenha.

Embora, a refrigeração do leite logo após a ordenha seja uma medida obrigatória, isto não garante a qualidade do produto, reforçando que o mesmo seja obtido em condições higiênicosanitárias adequadas para reduzir a possibilidade de contaminação inicial. Desta forma, a baixa temperatura pode manter a contagem microbiana em níveis reduzidos (Miguel et al. 2010).

Segundo a Instrução Normativa 62 (BRASIL 2011), admite-se o transporte do leite em latões ou tarros e em temperatura ambiente, desde que o leite seja entregue ao estabelecimento processador no máximo até duas horas após a conclusão da ordenha. $\mathrm{O}$ estabelecimento industrial que receber o leite em latões deverá realizar todas as análises exigidas para leite de conjunto. Entretanto, verificou-se no momento da coleta das amostras que este procedimento não é adotado nos estabelecimentos roraimenses que compram este leite.

Outro fator importante que indica a qualidade de um leite é a sua acidez, que está relacionada com o seu estado de conservação.

Tabela 2. Média e desvio padrão dos resultados de $\mathrm{pH}$, temperatura, acidez em termos de ácido láctico e graus Dornic, estrato seco total e cálcio obtidos nas amostras de leite in natura fluido coletadas nos municípios de Cantá (CT), Boa Vista (BV) e Alto Alegre (AL), Roraima.

\begin{tabular}{|c|c|c|c|c|c|c|}
\hline \multirow{2}{*}{ Amostra } & \multirow{2}{*}{ pH } & \multirow{2}{*}{$\begin{array}{c}\text { Temp. } \\
{ }^{\circ} \mathrm{C}\end{array}$} & \multicolumn{2}{|c|}{ Acidez } & \multirow{2}{*}{$\begin{array}{c}\text { Extrato seco } \\
\text { total } \\
\% \\
\end{array}$} & \multirow{2}{*}{$\begin{array}{c}\text { Cálcio } \\
\mathrm{mg} / 100 \mathrm{~mL}\end{array}$} \\
\hline & & & g A.L./100mL & ${ }^{\circ} \mathrm{D}$ & & \\
\hline CT1 & 6,69 & 29,20 & $0,156 \pm 0,005$ & $21,0 \pm 0,57$ & $34,28 \pm 10,42$ & $123,50 \pm 1,10$ \\
\hline $\mathrm{CT} 2$ & 6,64 & 28,30 & $0,132 \pm 0,005$ & $19,0 \pm 0,57$ & $13,16 \pm 0,36$ & $107,50 \pm 6,10$ \\
\hline $\mathrm{CT} 3$ & 6,77 & 28,60 & $0,120 \pm 0,005$ & $17,0 \pm 0,57$ & $21,33 \pm 9,77$ & $104,30 \pm 8,90$ \\
\hline CT4 & 6,79 & 28,80 & $0,102 \pm 0,005$ & $15,0 \pm 0,00$ & $35,60 \pm 2,31$ & $90,80 \pm 6,50$ \\
\hline BV1 & 6,77 & 28,50 & $0,132 \pm 0,005$ & $23,0 \pm 2,08$ & $12,40 \pm 0,64$ & $105,40 \pm 6,70$ \\
\hline BV2 & 6,60 & 19,30 & $0,159 \pm 0,005$ & $21,0 \pm 0,00$ & $13,44 \pm 1,61$ & $80,80 \pm 5,10$ \\
\hline BV3 & 6,30 & 23,80 & $0,156 \pm 0,029$ & $18,0 \pm 0,00$ & $12,59 \pm 0,04$ & $70,80 \pm 2,30$ \\
\hline AL1 & 6,65 & 21,40 & $0,129 \pm 0,005$ & $20,0 \pm 2,64$ & $11,62 \pm 0,96$ & $48,40 \pm 3,60$ \\
\hline AL2 & 6,73 & 18,20 & $0,105 \pm 0,005$ & $17,0 \pm 1,15$ & $9,72 \pm 1,48$ & $40,60 \pm 1,60$ \\
\hline AL3 & 6,71 & 20,00 & $0,129 \pm 0,010$ & $19,0 \pm 0,00$ & $16,13 \pm 5,26$ & $55,30 \pm 2,60$ \\
\hline AL4 & 6,75 & 18,60 & $0,123 \pm 0,010$ & $17,0 \pm 0,58$ & $11,47 \pm 1,05$ & $49,20 \pm 1,00$ \\
\hline AL5 & 6,76 & 19,00 & $0,138 \pm 0,014$ & $19,0 \pm 0,58$ & $8,58 \pm 1,06$ & $52,90 \pm 0,80$ \\
\hline AL6 & 6,77 & 19,50 & $0,159 \pm 0,005$ & $24,0 \pm 0,58$ & $13,00 \pm 0,07$ & $53,60 \pm 0,90$ \\
\hline
\end{tabular}


Tabela 3. Média e desvio padrão dos resultados de $\mathrm{pH}$, temperatura, acidez em termos de ácido láctico e graus Dornic, estrato seco total e cálcio obtidos nas amostras de leite in natura fluido coletadas nos municípios de Cantá (CT), Boa Vista (BV) e Alto Alegre (AL), Roraima.

\begin{tabular}{|c|c|c|c|c|c|c|}
\hline Amostras & Etanol & Amido & Cloro & Água oxigenada & Colostro & Sacarose \\
\hline CT1 & Inst. & Neg. & Neg. & Neg. & C & Neg. \\
\hline CT2 & Est. & Neg. & Neg. & Neg. & NC & Neg. \\
\hline CT3 & Est. & Neg. & Neg. & Neg. & NC & Neg. \\
\hline CT4 & Inst. & Neg. & Neg. & Neg. & NC & Neg. \\
\hline BV1 & Est. & Neg. & Neg. & Neg. & NC & Neg. \\
\hline BV2 & Inst. & Neg. & Neg. & Neg. & NC & Neg. \\
\hline BV3 & Est. & Neg. & Neg. & Neg. & NC & Neg. \\
\hline AL1 & Est. & Neg. & Neg. & Neg. & NC & Neg. \\
\hline AL2 & Est. & Neg. & Neg. & Neg. & NC & Neg. \\
\hline AL3 & Est. & Neg. & Neg. & Neg. & NC & Neg. \\
\hline AL4 & Est. & Neg. & Neg. & Neg. & NC & Neg. \\
\hline AL5 & Est. & Neg. & Neg. & Neg. & NC & Neg. \\
\hline AL6 & Inst. & Neg. & Neg. & Neg. & NC & Neg. \\
\hline
\end{tabular}

Legenda: Inst. = Instável; Est. Estável; Neg. = Negativo C = Coagulou; $\mathrm{NC}=$ Não Coagulou.

Assim, uma acidez alta é o resultado da acidificação da lactose, que geralmente é provocada pela presença de microrganismos que se multiplicam no leite, sendo essa proliferação devido ao envelhecimento do leite e elevação da temperatura.

Segundo Tronco (2010), para se conhecer com exatidão a acidez, deve-se recorrer à titulação com hidróxido de sódio N/9 ou $0,11 \mathrm{~N}$ designada de soda Dornic. Avaliando as 13 amostras analisadas, verificou-se que $62 \%$ apresentaram teores de acidez fora dos padrões preconizados pela IN 62 (BRASIL 2011).

Os resultados obtidos nas amostras para a acidez indicam que o leite analisado possui baixa quantidade de microrganismos mesófilos, indicando que o mesmo foi obtido e transportado sob condições adequadas. O armazenamento e o transporte do leite a temperaturas inadequadas favorece a multiplicação dos microrganismos mesófilos, que transformam a lactose em ácido láctico, o qual é detectado na análise de acidez titulável (Moro 2012).

Gracindo \& Pereira (2009), afirmam ainda, que o resfriamento do leite é uma das medidas que exerce maior impacto sobre a qualidade do leite imediatamente após a ordenha, pois inibe o crescimento e a multiplicação da maioria dos microrganismos do leite. Desta forma, acreditase que em algumas amostras à exposição excessiva à temperatura ambiente, favoreceu o crescimento de microrganismos que acidificam o leite, tendo em vista que grande parte do leite comercializado nos municípios onde foi realizada a pesquisa não sofre nenhum processo de refrigeração após a ordenha, e ficam expostos ao sol em latões durante toda a sua comercialização.

Avaliou-se também a percentagem de matéria seca ou extrato seco, que é indispensável para avaliar a integridade de um leite, e segundo a Instrução Normativa 51 (BRASIL 2002), um leite normal deve apresentar um mínimo de $11,41 \%$ de extrato seco total.

Observando os resultados, percebe-se que o mínimo recomendando é de $11,5 \%$ não foi atingido pelas amostras AL2 e AL5. E as amostras CT1 e CT4 ficaram com teores elevados podendo ter ocorrido influência de fatores externos, como a umidade, por exemplo. A diminuição do teor de extrato seco total reflete, possivelmente, em uma alimentação deficiente do rebanho (Mühlbach 2003).

Os principais minerais encontrados no leite são o cálcio e o fósforo, que são utilizados em grandes quantidades pelo animal neonato para o crescimento de ossos e o desenvolvimento de tecidos macios, que estão basicamente associados com a estrutura das micelas de caseína (Peres 2001). Normalmente, o cálcio pode ser utilizado para monitorar a nutrição e o metabolismo de vacas leiteiras. Não 
metabolismo de vacas leiteiras. Não desconsiderando a importância, na alimentação humana, do cálcio encontrado no leite de vaca, que é muito importante sob o ponto de vista nutricional e tecnológico na elaboração de produtos lácteos.

Em relação aos valores de cálcio encontrado nas amostras analisadas, bem como o valor mínimo aceitável de cálcio em miligramas por $100 \mathrm{~mL}$ de leite, verificou-se que $100 \%$ das amostras encontram-se abaixo do mínimo de $\mathrm{mg} / 100 \mathrm{~mL}$, possivelmente os animais dessas propriedades rurais estão se alimentando de forma inadequada sem os nutrientes necessários para seu desenvolvimento e produção leiteira.

$\mathrm{O}$ cálcio faz parte do grupo dos macrominerais ou minerais principais, aqueles exigidos em grandes quantidade (g/dia) e presente no tecido do animal em altas concentrações. Segundo Gonçalves (2009), as exigências de cálcio parecem ser superiores às de fósforos em animais jovens, tornando-se equilibradas em animais adultos.

Avaliou-se também a instabilidade do leite através do teste do álcool, ou seja, que o leite produzido nas propriedades rurais deve apresentar resultado negativo na prova do álcool, ou seja, não deve formar grumos quando misturado a igual volume de solução de etanol em concentrações pré-estabelecidas. O leite com resultado positivo no teste é considerado com baixa resistência, podendo coagular nas placas do pasteurizado durante o tratamento (Oliveira \& Timm 2007). As análises constataram que $50 \%$ das amostras do município de Cantá, 33\% de Boa Vista e 17\% de Alto Alegre, encontravam-se instável para a prova do álcool.

Segundo Tronco (2010), a prova do etanol se baseia na ação desidratante do álcool, desde que o leite apresente uma acidez ligeiramente superior a $20^{\circ} \mathrm{D}$ ou $\mathrm{pH}$ entre 6,3 a 6,4 . Entretanto, analisando o resultado da prova do etanol com os resultados obtidos da acidez e $\mathrm{pH}$, a amostra CT4 não se encaixa nesses padrões pré-estabelecidos, pois se encontra com acidez média de $15^{\circ} \mathrm{D}$, dentro dos parâmetros, mas seu resultado foi positivo prova do etanol.

Contudo, Zanela (2004) afirma que a principal alteração identificada no leite instável não-ácido (LINA) é a perda da estabilidade da caseína ao teste do álcool, resultando em precipitação positiva, sem haver acidez elevada do leite. Ainda segundo o autor, os resultados positivos podem ocorrer devido à redução de $\mathrm{pH}$, fermentação da lactose até a produção de ácido láctico, o que resulta na instabilidade da caseína.

$\mathrm{Na}$ pesquisa de leite colostral a tabela 3 mostra que das 13 amostras coletadas apenas uma (CT1) coagulou na adição de álcool a 60\% $\mathrm{v} / \mathrm{v}$. Esse tipo de leite é proibido para aproveitamento para fins de alimentação humana (RIISPOA 1980) e não deve ser misturado ao leite normal, por ser de fácil deteriorização (Vieira et al. 2005).

Com relação a substâncias conservadoras e/ ou inibidoras (água oxigenada e cloro e hipocloritos) e substâncias reconstituintes da densidade (amido e sacarose) o resultado foi negativo para todas as amostras, ou seja, 100\% das amostras não possui nenhuma dessas substâncias estranhas ou fraudulentas em sua composição.

\section{Análises microbiológicas}

Os resultados encontrados para as análises microbiológicas estão apresentados na Tabela 4. As amostras em geral, não apresentaram resultados satisfatórios para presença de Coliformes Totais, Fecais e Salmonela à temperatura ambiente, ou seja, na temperatura que o leite é comercializado. Observa-se que na Tabela 4, das 13 amostras analisadas, $100 \%$ indicaram presença de coliformes totais, $85 \%$ apresentaram coliformes fecais e $77 \%$ a presença de salmonela.

Segundo Rodrigues et. al. (2012), as salmonelas são transmitidas ao homem através da ingestão de alimentos contaminados com fezes de animais, sendo que a manipulação desses alimentos por pessoas contaminadas também podem causar sua contaminação. Conforme a legislação brasileira em vigor, o alimento que for determinado com presença de salmonela encontra-se impróprio para o consumo humano.

No Brasil a legislação vigente não estabelece para o leite in natura limite máximo para presença de coliformes totais e coliformes fecais. Essa situação pode advir da proibição da venda de leite in natura diretamente ao consumidor, em conformidade com o Decreto $n^{0} 66.183 / 70$ (BRASIL 1970).

A presença de coliformes encontrados no leite in natura é tomada como indicadora de condições higiênicas inadequadas, principalmente durante a ordenha, colocando 
Tabela 4. Resultado das análises microbiológicas para coliformes totais (CT), coliformes fecais (CF) e Salmonela, em UFC/100 mL, realizadas nas amostras de leite in natura fluido coletadas nos municípios de Cantá (CT), Boa Vista (BV) e Alto Alegre (AL), Roraima.

\begin{tabular}{|c|c|c|c|c|c|c|c|}
\hline \multirow{2}{*}{ Amostra } & \multirow{2}{*}{$\begin{array}{c}\text { Data } \\
\text { coleta }\end{array}$} & \multicolumn{4}{|c|}{ Temperatura Ambiente } & \multicolumn{3}{c|}{ Após 100 C } \\
\cline { 3 - 8 } & & $\mathrm{CT}$ & $\mathrm{CF}$ & $\begin{array}{c}\text { Salmonela } \\
(\mathrm{UFC} / 100 \\
\mathrm{mL})\end{array}$ & $\begin{array}{c}\mathrm{CT} \\
(\mathrm{UFC} / 100\end{array}$ & $\begin{array}{c}\text { CF } \\
(\mathrm{UFC} / 100\end{array}$ & $\begin{array}{c}\text { Salmonela } \\
\text { (UFC/100 } \\
\mathrm{mL})\end{array}$ \\
\hline CT1 & $23 / 07 / 2013$ & 2000 & 1200 & 400 & Ausente & Ausente & Ausente \\
\hline CT2 & $23 / 07 / 2013$ & 2800 & 600 & 800 & Ausente & Ausente & Ausente \\
\hline CT3 & $23 / 07 / 2013$ & 2500 & 700 & Ausente & Ausente & Ausente & Ausente \\
\hline CT4 & $23 / 07 / 2013$ & 2000 & 300 & 1000 & Ausente & Ausente & Ausente \\
\hline BV1 & $23 / 07 / 2013$ & 1900 & 1000 & 600 & Ausente & Ausente & Ausente \\
\hline BV2 & $30 / 07 / 2013$ & 1300 & 1000 & Ausente & Ausente & Ausente & Ausente \\
\hline BV3 & $30 / 07 / 2013$ & 4500 & 2500 & 2600 & Ausente & Ausente & Ausente \\
\hline AL1 & $07 / 08 / 2013$ & 1400 & 100 & Ausente & 100 & Ausente & Ausente \\
\hline AL2 & $07 / 08 / 2013$ & 900 & Ausente & 100 & 500 & Ausente & Ausente \\
\hline AL3 & $07 / 08 / 2013$ & 42.667 & Ausente & 4500 & Ausente & Ausente & Ausente \\
\hline AL4 & $07 / 08 / 2013$ & 4500 & 400 & 900 & 100 & Ausente & Ausente \\
\hline AL5 & $07 / 08 / 2013$ & 4900 & 800 & 4500 & Ausente & Ausente & Ausente \\
\hline AL6 & $07 / 08 / 2013$ & 2400 & 1100 & 1500 & 800 & Ausente & Ausente \\
\hline
\end{tabular}

Legenda: UFC = Unidade Formadora de Colônias.

em risco o produto obtido pela possibilidade da coexistência de espécies patogênicas (Oliveira \& Timm 2007). Entretanto, sabe-se que todos os microrganismos envolvidos nesse estudo são mesófilos e tal contaminação pode ser minimizada se o leite for submetido à fervura (BRASIL 1970).

Isso ficou evidenciado após a fervura das amostras, onde pode ser confirmado que houve redução brusca na presença de Coliformes Totais nas amostras de Alto Alegre, e nas amostras de Cantá e Boa Vista 100\% das amostras não se constatou a presença destas bactérias. E para Coliformes Fecais e Salmonela, verificou-se a ausência em $100 \%$ das amostras analisadas após o leite ter sido submetido a uma temperatura de $100^{\circ} \mathrm{C}$.

\section{Avaliação dos questionários aplicados aos produtores}

Avaliando a resposta de 10 questionários respondidos pelos produtores onde foram coletadas as 13 amostras coletadas, os resultados mostraram que $100 \%$ dos produtores ordenham suas vacas todos os dias no mesmo horário, variando entre $3 \mathrm{~h} 00 \mathrm{~min}$ e $06 \mathrm{~h} 00 \mathrm{~min}$, apenas um produtor retira o leite fora deste horário, entre $08 \mathrm{~h} 00 \mathrm{~min}$ e $10 \mathrm{~h} 00 \mathrm{~min}$.

Além disso, 90\% dos produtores afirmam que limpam os utensílios antes do processo de ordenha, apenas um produtor (o único analisado que trabalha com ordenha mecanizada), que não faz a higienização antes do processo. Além disso, $100 \%$ dizem que realizam a higienização após a obtenção do leite e a limpeza é realizada geralmente com água e sabão, $50 \%$ dos produtores responderam que higienizam o material escaldando-os. E $80 \%$ dos produtores disseram ferver o leite e o consomem com seus familiares, $40 \%$ utilizam o leite para a fabricação de queijos, no qual são armazenados em latões (geralmente, plástico, zinco e alumínio).

Um dos produtores se destaca quanto à média de leite (oriundo de três propriedades rurais) vendida para $\mathrm{o}$ consumidor final $\mathrm{e}$ estabelecimentos comerciais, produzindo cerca de 400L/dia, sendo que no restante dos produtores a média de leite produzido é de 46 
litros/dia. Relataram também que $80 \%$ do leite produzido é fornecido para estabelecimentos comerciais, como padarias, lanches, fabricação de sorvetes e iogurtes. Destacaram ainda que o leite produzido geralmente não sobra, e que quando isso ocorre e azeda o leite é utilizado na dieta dos animais da propriedade rural.

Do total das amostras analisadas, $85 \%$ são vendidas in natura (em saquinhos plásticos, garrafa PET e vasilhas levadas pelo próprio consumidor) e, $15 \%$ somente para a fabricação de queijos (derivado lácteo).

\section{CONCLUSÕES}

Os resultados obtidos nas análises físicoquímicas para as amostras avaliadas de leite in natura ou cru fluido comercializado nos municípios de Cantá, Boa Vista e Alto Alegre, indicaram que $62 \%$ das amostras, em relação à acidez, apresentaram-se em desacordo com a Instrução Normativa 62 /2011, e 31\% demonstraram resultados instáveis à prova do álcool. Entretanto, $85 \%$ das amostras estão acima do mínimo aceitável pela legislação nos parâmetros do extrato seco total e $92 \%$ não reagiram a prova da pesquisa colostral, sendo que apenas uma amostra coagulou com aparecimento de flocos.

As análises para adição de substâncias fraudulentas foi negativo em $100 \%$ das amostras. Por outro lado, foi observado que $100 \%$ das amostras não estão sendo refrigeradas de acordo com a legislação e não atingem a quantidade mínima indicada de mg de Cálcio para cada $100 \mathrm{~mL}$ de leite. Ademais, as 13 amostras analisadas apresentaram presença de coliformes totais em 100\% das amostras, coliformes fecais em $85 \%$, e $77 \%$ das amostras indicaram a presença de salmonela, que pode contribuir para o desencadeamento de surtos de toxi-infecções alimentares.

Portanto, de forma geral, o leite in natura ou cru fluido analisado não apresentaram resultados satisfatórios, com isso, os produtores devem procurar se adequar as legislações vigentes, buscando melhorar a qualidade higiênico-sanitária do seu produto, para assim, oferecer ao consumidor um alimento confiável e saudável.

\section{AGRADECIMENTOS}

Este trabalho foi financiado pelo Conselho
Nacional de Desenvolvimento Científico e Tecnológico - CNPq, Processo 015/2013.

\section{REFERÊNCIAS BIBLIOGRÁFICAS}

Brasil. Ministério da Agricultura, Pecuária e Abastecimento, Instrução Normativa $\mathrm{N}^{\circ} 51$ de 18 de setembro de 2002.

. Decreto $\mathrm{n}^{\circ} 66.183$ de 05 de fevereiro de 1970.

Regulamenta o Decreto-Lei $n^{\circ}$. 923, de 10 de outubro de 1969 que dispõe sobre a comercialização de leite cru. Brasília, 1970.

. Instrução Normativa $n^{\circ} .62$, de 29 de dezembro

de 2011. Alterar o caput, excluir o parágrafo único e inserir os $\S \S 1^{\circ}$ ao $3^{\circ}$, todos do art. $1^{\circ}$, da Instrução Normativa MAPA n ${ }^{\circ} 51$, de 18 de setembro de 2002. Diário Oficial da República Federativa do Brasil, Brasília, DF, 30 dez. 2011. Seção 1.

Instrução Normativa $n^{\circ}$. 68, de 29 de 12 dezembro de 2006. Oficializa os métodos analíticos oficiais físico-químicos, para controle deleite e produtos lácteos. Diário Oficial da República Federativa do Brasil, Brasília, DF, 14 dez. 2006.

Ministério da Agricultura. Regulamento da inspeção industrial e sanitária de produtos de origem animal. (aprovado pelo Decreto 30.691 de 29/03/52 e alterado pelo Decreto 1255 de 25/06/962). Brasília, 1980. 66p.

Fiuza, F. 2016. Consumo de leite clandestino volta a ser discutido nacionalmente. Disponível em: [http:// inovadefesa.ning.com/profiles/blogs/consumo-deleite-clandestino]. Acessado em: 17 de junho de 2016.

Gonçalves, L.C.; Borges, I. \& Ferreira, P.D.S. 2009. Alimentação de Gado de Leite. FEPMVZ, Belo Horizonte, $150 \mathrm{p}$.

Gracindo, A.P.A.C. \& Pereira, G.F. 2009. Produzindo leite de alta qualidade. $1^{\mathrm{a}}$ ed. Empresa de Pesquisa Agropecuária do RN, Rio Grande do Norte, 120p.

IBGE- Instituto Brasileiro de Geografia e Estatística. Estatística da Produção Pecuária. 2012. Disponível em: $\quad$ http://saladeimprensa.ibge.gov.br/noticias? view $=$ noticia\&redirecionado $=1 \& \mathrm{id}=1 \&$ busca $=1 \& \mathrm{idn}$ $\underline{\text { oticia }}=$. Acessado em 12 de junho de 2016.

Instituto Adolfo Lutz. 2005. Normas Analiticas do Instituto Adolfo Lutz. $3^{\text {nd }}$ ed. O Instituto, São Paulo, $650 \mathrm{p}$.

Mendes, C.G.; Sakamoto, S.M.; Silva, J.B.A.; Jácome, C. G.M. \& Leite, A.I. 2010. Análise Físico-químicas e Pesquisa de Fraude no Leite Informal Comercializado no Município de Mossoró - RN. Ciência Animal Brasileira. 11(2):349-356.

Miguel, G.Z.; Magalhães, M.C.; Geron, L.J.V.G.; Botini, T.; Saenz, E.C. \& Cruz, C. 2010. Caracterização Físico-química de leite obtido de diferentes tipos de 
comercialização em Pontes de Lacerda -MT. Revista de Ciências Agroambientais 8(1):103-111.

Moro, G. 2012. Qualidade do leite na região nordeste do Rio Grande do Sul: níveis de resíduos de agrotóxicos e medicamentos veterinários. Dissertação de mestrado, Universidade Federal de Santa Maria, Santa Maria, 250p.

Mühlbach, P.R.F. 2003. Nutrição da vaca em lactação e a qualidade do leite.Simpósio de Bovinocultura de Leite,1, [s.1.]. Sociedade Catarinense de Medicina Veterinária/ Núcleo Oeste.

Müller, E.E. 2002. Qualidade do leite, células somáticas $e$ prevenção da mastite. Anais do II Sul-Leite: Simpósio sobre Sustentabilidade da Pecuária Leiteira na Região Sul no Brasil/editores Geraldo Tadeu dos Santos et. al. - Maringá: UEM/CCA/DZO NUPEL. 206-2017.p Toledo - PR. [acesso 2015 Ago 12]. Disponível em: [http://www.nupel.uem.br/ qualidadeleitem.pdf].

Oliveira, D.S. \& Timm, C.D. 2007. Instabilidade da caseína em leite sem acidez adquirida. Revista Portuguesa de Ciências Veterinárias. 102(561562):12-22.

Peres, J.R. 2001. O leite como ferramenta do monitoramento nutricional. In: González, FHD; Dürr, JW; Fontaneli, RS. (Ed.). Uso do leite para monitorar a nutrição e metabolismo de vacas leiteiras. Ed. da UFRGS, Porto Alegre. p.29-43.

Rodrigues, R.J.O.; Sant'Anna, M.E.B.; Cordeiro, S.M.; Pinheiro, D.P.M. \& Tigre, D.M. 2012. Qualidade microbiológica do leite in natura comercializado na cidade de Castro Alves - BA. Revista de Ciência Médicas e Biológicas. 11(3):306-310.

Santos, J.M. 2010. Leite cru refrigerado: características físico-químicas, microbiológicas e desenvolvimento de microorganismos psicotróficos. Dissertação de mestrado. Universidade Federal dos Vales do Jequitinhonha e Mucuri, Diamantina. 195p.

Trevisan, A.P. 2008. Influência de Diferentes Concentrações de Enzimas Lactase e Temperatura sobre a Hidrólise de Lactose em Leite Pasteurizado. Dissertação de mestrado. Universidade Federal de Santa Maria, Santa Maria. 195p.

Tronco, V.M. 2010. Manual para Inspeção de qualidade do leite. $4^{\mathrm{a}}$ ed. Ed.UFSM, Santa Maria. 225p.

Vieira, L.C.; Kaneyoshi, C.M. \& Freitas, H. 2005. Criação de gado leiteiro na Zona de Bragantina. Embrapa Amazônia Oriental, Belém. Disponível em: [http://sistemasdeproducao.cnptia.embrapa.br/ FontesHTML/Leite/GadoLeiteiroZonaBragantina/ paginas/qualidade.htm]. [acesso $2015 \mathrm{Ago} 12$ ].

Vogel,A.I. 2002. Análise Química Quantitativa. 6a ed. LTC - Livros Técnicos e Científicos: Rio de Janeiro. $680 \mathrm{p}$.

Zanela, M.B. 2004. Caracterização do leite produzido no
Rio Grande do Sul, ocorrência e indução experimental do leite instável não ácido (LINA). Tese de doutorado. Universidade Federal de Pelotas, Pelotas. 325p.

Zoccal, R.; Alves, E.R. \& Gasques, J.G. 2011. Diagnóstico da Pecuária de Leite Nacional. 2011. Disponível em: < http://www.cnpgl.embrapa.br/ nova/Plano Pecuario 2012.pdf $>$. Acesso em: 06 set. 2016. 